\title{
Role of natural killer cells in liver transplantation treatment of liver cancer
}

\author{
WENBIN JI ${ }^{1}$, JIN CHEN $^{1}$, YUCHE MI ${ }^{1}$, GUILIANG WANG ${ }^{1}$, XINJIANG XU ${ }^{1}$ and WEIZHENG WANG ${ }^{2}$ \\ Departments of ${ }^{1}$ Radiology and ${ }^{2}$ Vascular Surgery, Taizhou Hospital of Wenzhou Medical University, \\ Taizhou, Zhejiang 317000, P.R. China
}

Received January 8, 2016; Accepted February 10, 2017

DOI: $10.3892 /$ etm.2017.4748

\begin{abstract}
Liver cancer caused by diet or life style is a significant public health problem. Liver transplantation (LT) is a commonly used method of treatment for the liver cancer. The present study aimed to determine whether assessing the net state of natural killer (NK) cell function following LT distinguishes patients at risk for transplantation rejection. A total of 53 patients were involved; all underwent LT for hepatocellular carcinoma with $(n=13)$ or without $(n=40)$ transplantation rejection. The density of interferon- $\gamma($ IFN- $\gamma$ ) in blood serum was examined and patients were divided into two groups: Higher (H) and lower (L), on the basis of IFN- $\gamma$ density. The percentage of NK cells and their producing cytokines was detected using fluorescence-activated cell sorting in peripheral blood and liver samples. As evaluation indexes of liver function, aspartate transaminase (AST) and alanine transaminase (ALT) were detected in blood serum. NK cell activation of the H-group was observed to be higher than the L-group, specifically the expression of NK group 2D, cluster of differentiation 69 and IFN- $\gamma$ were higher than the L-group. The H-group exhibited a higher level of AST and ALT, which indicates the potential for acute transplantation rejection. The results of the present study indicate that NK cells and NK-derived IFN- $\gamma$ serve an important function in regulating the rejection of LT and tumor metastasis in response to LT.
\end{abstract}

\section{Introduction}

Hepatocellular carcinoma (HCC) is the second most common cancer type worldwide, and its incidence in Asia is rising (1). Liver transplantation (LT) is a well-established therapy with curative potential for terminal stages of HCC (2). It was initially a high-risk procedure; however, compared with

Correspondence to: Dr Weizheng Wang, Department of Vascular Surgery, Taizhou Hospital of Wenzhou Medical University, 150 Ximen Street, Taizhou, Zhejiang 317000, P.R. China

E-mail: wangweizheng126@sina.com

Key words: liver transplantation, natural killer cell, liver cancer, hepatocellular carcinoma, interferon- $\gamma$ surgical techniques and emerging immunosuppressive therapy, it is the only therapy that results in significant improvements in the post-transplantation survival rate. Some studies report one-year and ten-year survival of LT are 83-88\% and $68-72 \%$, respectively (3-7). LT for early stage HCC is based on the Milan criteria, which has demonstrated a lower risk of recurrence in patients with a single lesion $<5 \mathrm{~cm}$ or up to 3 nodules $<3 \mathrm{~cm}$ each (8). Other predictors of HCC recurrence, independent of tumor size and in the absence of extra-hepatic spread, are macro- and microvascular invasion, bilobar involvement, stage of differentiation, lymph node positivity, total tumor volume and rate of tumor growth (9-13).

Liver transplant technology has been undergoing constant improvement globally, leading to a decrease in perioperative mortality and an increased survival rate for patients undergoing LT. However, there are numerous types of transplantation postoperative complications, such as requisite immunosuppression treatment and post-transplant recurrences, leading to poor quality of life $(14,15)$.

Cell-mediated immune function has been demonstrated to be a contributor to tumor progression and invasion (16). Furthermore, in the post-LT period, the risk of recurrent HCC has been demonstrated to have an association with cumulative cluster of differentiation (CD) $4^{+} \mathrm{T}$-cell function following LT for cirrhosis and HCC (13). It has been indicated that monitoring cumulative $\mathrm{CD}^{+}{ }^{+} \mathrm{T}$-cell function following LT may be a beneficial way to predict which patients are at the highest risk for HCC recurrence (13). Natural killer (NK) cells are of lymphoid origin and serve key roles in the elimination of host viral infections in addition to tumor cell development which account for the majority of the liver innate immune cells $(17,18)$. NK cells are known to secrete cytokines, including interferon- $\gamma(\mathrm{IFN}-\gamma)$ in response to stimulation (19). This regulation by cytokines has formed the basis of a number of different therapeutic approaches to activate NK cells using the infusion of allogeneic haploidentical NK donor cells to treat cancer (20-22).

In a previous study, a marked difference between concentrations of IFN- $\gamma$ in the serum of each patient was identified (23). Therefore, in the present study patients were divided into two groups on the basis of IFN- $\gamma$ density. The number and activation of NK cells was compared between the two groups, so as to assess the change of liver function following LT. The specific aims of the current study were to assess the risk of 
IFN- $\gamma$ enrichment based on serially monitored NK cell function following LT, and to evaluate the predictive value of NK cell function suppression in the identification of post-LT HCC recurrence.

\section{Patients and methods}

Patients. A total of 53 patients (31 male and 22 female) were recruited to this historical cohort study and all adult patients (age, 18-55 years; mean, 46.9 years) who underwent LT from January 2009 to September 2013 for HCC were eligible. The patients who had severe disease not correlated with malignancy, such as cardiac disease, severe hypertension and renal disease, and whose data was not complete were excluded. All patients provided informed consent. Patients were diagnosed based on classical radiological features of venous washout with raised $\alpha$-fetoprotein and arterial enhancement and 13 patients received histological confirmation or biopsy of surgical specimens. Follow-up of these patients was made from 1 month to 3 years after surgery. The data of consecutive patients who met the conditions from January 2009 to September 2013 were included in this study. The data of cytokines collected in the 6th month after LT were shown in the figures.

Patients were divided into two groups according to the density of IFN- $\gamma$ in the serum, which was assessed by ELISA: high in IFN group (H-IFN; IFN- $\gamma,>50 \mathrm{pg} / \mathrm{ml}, \mathrm{n}=29)$ and low in IFN group (L-IFN; IFN- $\gamma, \leq 50 \mathrm{pg} / \mathrm{ml}, \mathrm{n}=24$ ). The present study was approved by the Institutional Review Board of Taizhou Hospital of Wenzhou Medical University (Taizhou, China)

Cell isolation. Liver tissues, which were obtained through liver transplant surgery, were cut into pieces and incubated in Eagle's minimum essential medium (MEM; Gibco; Thermo Fisher Scientific, Inc., Grand Island, NY, USA) supplemented with $5 \mathrm{mM}$ HEPES (Sigma-Aldrich; Merck KGaA, Darmstadt, Germany), 0.1\% collagenase and $0.01 \%$ Trypsin inhibitor (Sigma-Aldrich; Merck KGaA). The resultant finely minced liver tissue was stirred gently in the presence of $0.05 \%(\mathrm{~m} / \mathrm{v})$ collagenase II (Gibco; Thermo Fisher Scientific, Inc.) solution in a $37^{\circ} \mathrm{C}$ water bath for $15 \mathrm{~min}$. The enzymatically digested liver tissue was pressed through a 200-gauge stainless steel mesh into single-cell suspension, which was washed with PBS twice, then suspended in MEM containing $5 \mathrm{mM}$ HEPES and 5\% heat-inactivated fetal calf serum (Shenzhen Front Biomedical Co., Ltd., Shenzhen, China). Liver cell suspensions were overlaid on Ficoll-Paque (GE Healthcare Bio-Sciences, Pittsburgh, PA, USA) and centrifuged at $523 \mathrm{x} \mathrm{g}$ at $4^{\circ} \mathrm{C}$ for $10 \mathrm{~min}$. Hepatic mononuclear cells were collected from the interface using a pipette, washed twice with PBS and suspended in MEM. Peripheral blood mononuclear cells were obtained by Ficoll-Paque gradient centrifugation (24) and isolated from heparinized blood. Following centrifugation, cells were washed with phosphate-buffered saline (Gibco; Thermo Fisher Scientific, Inc.) containing $0.5 \%$ heat-inactivated FCS and counted using a hemocytometer; $0.4 \%$ trypan blue exclusion (Beijing Solarbio Science \& Technology Co., Ltd., Beijing, China) was used according to the manufacturer's protocols to determine the viability of cells.
Flow cytometric analysis. For cell surface staining, cells were harvested and blocked with anti-Fc $\gamma$ receptor $(\mathrm{Fc} \gamma \mathrm{R})$ monoclonal antibody (cat. no. 4325-FC; R\&D Systems, Inc., Minneapolis, MN, USA) $\left(1 \mu \mathrm{g} / 10^{6}\right.$ cells $)$ at $4^{\circ} \mathrm{C}$ for $45 \mathrm{~min}$. For intracellular cytokine staining, cells were cultured in Roswell Park Memorial Institute 1640 medium (Gibco; Thermo Fisher Scientific, Inc.) containing 10\% FCS and treated with monensin (diluted with Dulbecco's modified Eagle's medium to concentration of $10 \mu \mathrm{g} / \mathrm{ml}$; Sigma-Aldrich; Merck KGaA) for $4 \mathrm{~h}$ to inhibit extracellular cytokine secretion. The presence of IFN- $\gamma$ was determined by intracellular flow cytometry. The antibodies used were as follows: Fluorescein isothiocyanate-conjugated NK1.1 (cat. no. FAB22252P), phycoerythrin (PE)-conjugated CD69 (cat. no. FAB23591P), IFN- $\gamma$ (cat. no. 285-IF) or NK group 2D (NKG2D, cat. no. 1299-NK), PE-cy5.5-conjugated CD3 (cat. no. MAB100) (all from R\&D Systems, Inc.). All mAbs were used at a final concentration of $10 \mu \mathrm{g} / \mathrm{ml}$. The cells were washed three times in washing buffer and resuspended in PBS after incubation for $30 \mathrm{~min}$ at $4^{\circ} \mathrm{C}$. All stained cells were analyzed using a FACScalibur ${ }^{\mathrm{TM}}$ flow cytometer (BD Biosciences, Franklin Lakes, NJ, USA), and the data was processed with WinMDI 2.9 software (Scripps Research Institute, La Jolla, CA, USA).

Cytokine detection using ELISA. The levels of cytokines in the serum were detected using commercial ELISA kits, following the manufacturers' protocols. The kits used were as follows: IFN- $\gamma$ (Human IFN- $\gamma$ Quantikine ELISA kit, cat. no. DIF50), tumor necrosis factor- $\alpha$ (TNF- $\alpha$ ) (Human TNF- $\alpha$ Quantikine ELISA kit, cat. no. DTA00C), interleukin (IL)-1 $\beta$ (Human IL-1ß/IL-F2 Quantikine ELISA kit, cat. no. DLB50) (all from R\&D Systems, Inc.), aspartate transaminase (AST) (Human aspartate transaminase ELISA kit, cat. no. E-1128) and alanine transaminase (ALT) (Human alanine transaminase ELISA kit, cat. no. E-0741) (both from Shanghai Ji Mian Shiye Co., Ltd., Shanghai, China).

Statistical analysis. Results are expressed as the mean \pm standard deviation and were analyzed using Prism version 5.0 for Windows (GraphPad Software Inc., La Jolla, CA, USA). The Student's t-test was used to compare the differences between two different groups, and $\mathrm{P}<0.05$ was considered to represent a statistically significant difference.

\section{Results}

Clinical characteristics of patients. ELISA analysis in IFN- $\gamma$ from whole blood revealed that the level of IFN- $\gamma$ was different in every patient (Fig. 1). Therefore, the patients were divided into two groups: H-IFN for patients with an IFN- $\gamma$ level $>50 \mathrm{pg} / \mathrm{ml}(\mathrm{n}=29)$ and L-IFN, for patients with an IFN- $\gamma$ $\leq 50 \mathrm{pg} / \mathrm{ml}(\mathrm{n}=24)$. The clinical characteristics of the 53 patients are presented in Table I. No significant differences were observed in the age, gender, AST (median, $97.4 \mathrm{pg} / \mathrm{ml}$; range, 70-293 pg/ml vs. median, $106.5 \mathrm{pg} / \mathrm{ml}$; range, $74-229 \mathrm{pg} / \mathrm{ml}$ ) and ALT (median, $75 \mathrm{pg} / \mathrm{ml}$; range, 49-352 pg/ml vs. median, $72 \mathrm{pg} / \mathrm{ml}$; range, 47-235 pg/ml) in peripheral blood samples.

Cumulative post-LT IFN- $\gamma$ density predicts NK cell activation. Considering that NK cells are the primary source of IFN- $\gamma$ and 
Table I. Clinical characteristics of patients pre-liver transplant.

\begin{tabular}{lcccrr}
\hline Group & Patients & $\begin{array}{c}\text { Age, } \\
\text { years }\end{array}$ & $\begin{array}{c}\text { Gender } \\
\text { (male:female) }\end{array}$ & $\begin{array}{c}\text { AST (IU/ml), } \\
\text { median (range) }\end{array}$ & $\begin{array}{r}\text { ALT (IU/ml), } \\
\text { median (range) }\end{array}$ \\
\hline High IFN & 24 & $58 \pm 7.6$ & $14: 10$ & $97.4(70-293)$ & $75(49-352)$ \\
Low IFN & 29 & $53 \pm 9.2$ & $17: 12$ & $106.5(74-229)$ & $72(47-235)$ \\
\hline
\end{tabular}

No significant differences were observed for these parameters, $\mathrm{P}>0.05$. Data are presented as mean \pm standard deviation, unless stated otherwise. IFN, interferon- $\gamma$; AST, aspartate transaminase; ALT, alanine transaminase.

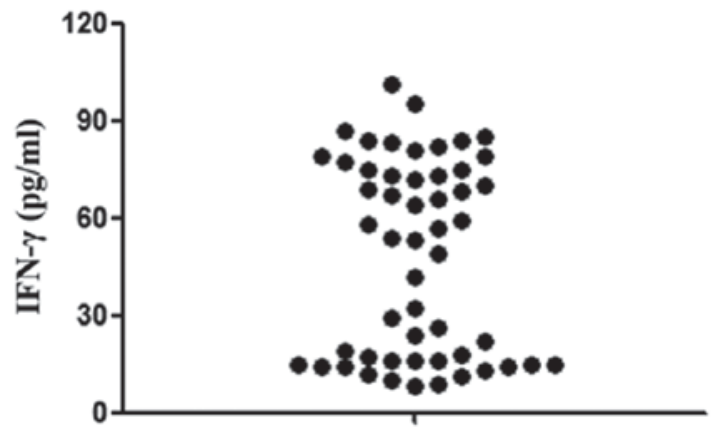

Figure 1. Density of IFN- $\gamma$ in peripheral blood serum of all patients was determined by ELISA. IFN- $\gamma$, interferon- $\gamma$.

account for the majority of liver innate immunocytes (25), the present study detected the number and expression of activation markers for NK cells six months post-LT by FACS flow cytometry. There was no significant difference between these two groups in the number of liver NK cells ( $\mathrm{P}=0.3734$; Fig. 2A). However, NK cells from the H-IFN group expressed higher levels of NKG2D, CD69 and IFN- $\gamma$ compared with the L-IFN group, which serve roles in the function of activating NK cells (NKG2D, $42.24 \pm 0.74$ vs. $28.94 \pm 0.72 \%$; CD $69,70.77 \pm 2.14$ vs. $46.80 \pm 1.23 \%$; IFN- $\gamma, 20.04 \pm 0.91$ vs. $9.24 \pm 0.77 \%, \mathrm{P}<0.001$; Fig. 2B-D).

Cumulative post-LT NK cell function predicts transplantation rejection and inflammation. A number of markers have been studied in order to identify a specific indicator of graft rejection following LT $(26,27)$. The present study assessed AST and ALT as indicators of graft rejection. Patients with a higher density of IFN- $\gamma$ had a lower AST:ALT ratio than those with lower density of IFN- $\gamma, 6$ months post-LT (AST, $1,074.00 \pm 98.93$ vs. $304.7 \pm 69.90, \mathrm{P}=0.0031$; ALT, $1,130.01 \pm 175.3$ vs. $349.0 \pm 72.17, \mathrm{P}=0.0146$; Fig. $3 \mathrm{~A}$ and $\mathrm{B})$. It has been demonstrated by Rodríguez-Perálvarez et al (28) that patients with moderate/severe acute cellular rejection (ACR) present with higher bilirubin levels and cholestasis parameters, with a lower AST:ALT ratio than those who present with mild or no ACR. Therefore, patients in the H-IFN group have a higher-risk of rejection.

The current study determined the cytokines associated with the patient's immune status. The expression of TNF- $\alpha$ and IL-1 $\beta$ in the H-IFN group was associated with the expression of IFN- $\gamma$. Furthermore, the expression levels of proinflammatory factors in the H-IFN group were significantly higher compared with the L-IFN group (TNF- $\alpha, 149.2 \pm 5.54$ vs. $62.97 \pm 2.70, \mathrm{P}=0.0002$; IL- $1 \beta, 115.3 \pm 8.45$ vs. $44.0 \pm 4.16$, $\mathrm{P}=0.0016$, respectively; Fig. $3 \mathrm{C}$ and $\mathrm{D})$. The aforementioned experimental results indicate that patients whose NK cells were inhibited sustained an improved quality of life.

\section{Discussion}

The current study assessed a cohort of 53 liver-transplanted recipients and investigated the phenotypic and functional features of NK cells and their association with the development of de novo cancer. The results of the present study indicate that NK cells from patients with differing densities of serum IFN- $\gamma$ present with distinctly impaired function. These changes are specifically evident in patients' 6 months post-LT and they may have the potential to affect the disease outcome. This highlights the potential that unique NK cells located in the liver are closely associated with maturation defects and uncommon patterns of cytokine production, leading to the development of de novo tumors or inflammation.

An increase of liver enzymes following transplantation is typically indicative of acute rejection. A previous study regarding the change of liver enzymes following transplantation demonstrated that patients with moderate/severe acute rejection present with higher bilirubin levels and cholestasis parameters, with a lower AST:ALT ratio than those with mild or no acute rejection (29). The patients whose density of IFN- $\gamma$ was higher had a lower AST/ALT level and therefore, patients with a higher density of IFN- $\gamma$ may suffer from moderate/severe acute rejection.

Following LT, the characteristics of the inflammatory environment, in which innate/acquired immune system recognition of the alloantigen takes place, determines the lineage commitment of immune cells (30). Thus, depending on the cytokines that are present when antigen activation occurs, innate immune cells including macrophages, dendric cells and NK cells, may acquire cytopathic and/or immunoregulatory phenotypes. TNF- $\alpha$ is primarily produced by monocytes or macrophages, it has been demonstrated that pre-transplant in vitro production of this molecule was significantly increased in patients with post-transplant acute rejection compared with those who did not develop acute rejection (31-34).

Regarding IFN- $\gamma$, in a previous study, Millán et al (35) evaluated the soluble production and intracellular expression of IFN- $\gamma$ in 47 LT patients. A pre-transplant cut-off value of 55.8\% for $\mathrm{CD} 8{ }^{+} \mathrm{IFN}-\gamma^{+}$identified patients at high risk of acute rejection (specificity, 82\%; sensitivity, 75\%). In the first week following transplantation, patients with a percentage of inhibition for 

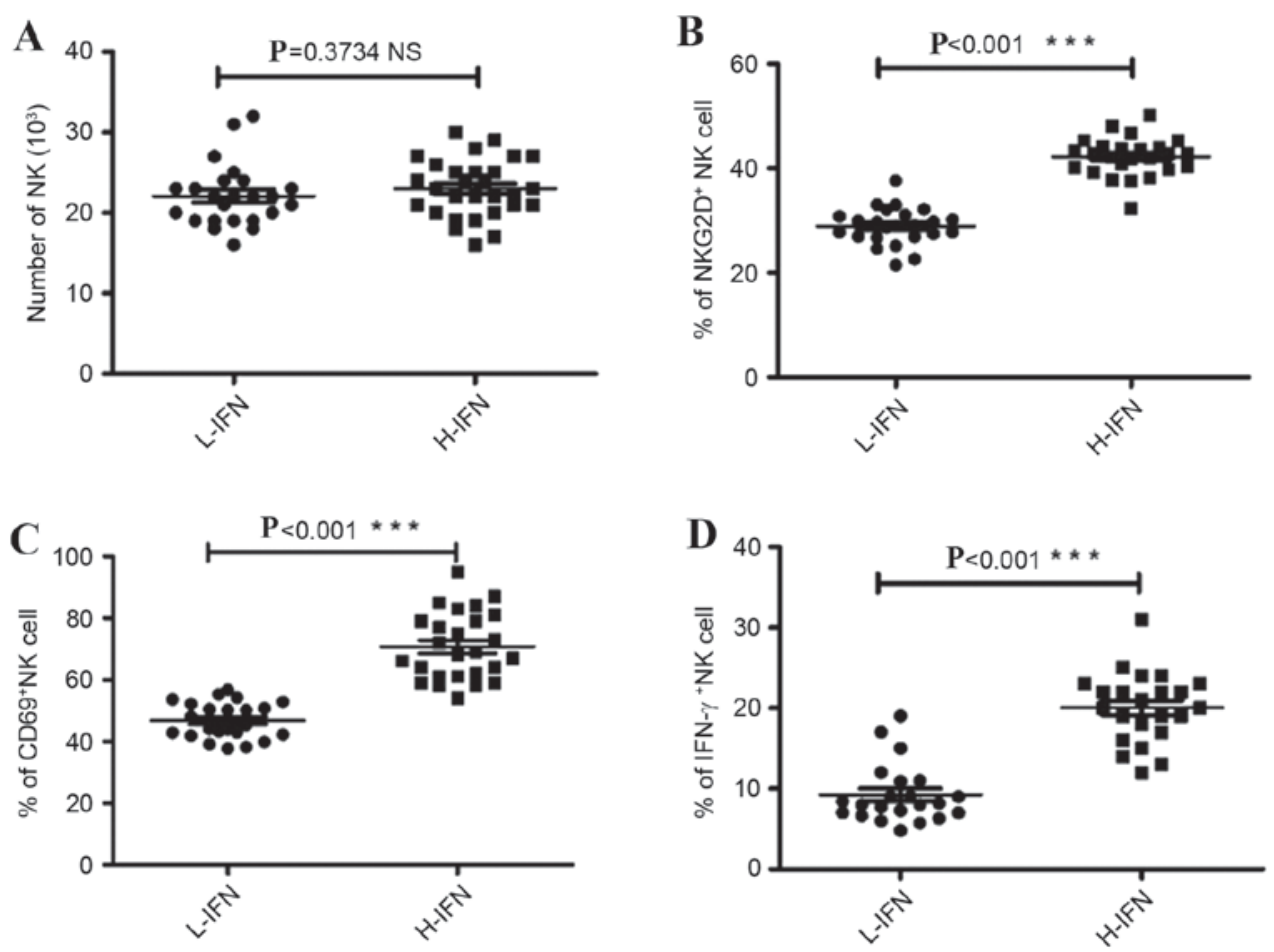

Figure 2. Activation of liver NK cells was detected using flow cytometry. (A) Number of NK cells in 105 CD $45^{+}$cells was compared between L-IFN and H-IFN groups. Expression of activation markers (B) NKG2D, (C) CD69 and (D) IFN- $\gamma$ in NK cells. ${ }^{* * *} \mathrm{P}<0.001$. NK, natural killer; CD, cluster if differentiation; IFN- $\gamma$, interferon- $\gamma$; L-IFN, low in IFN group; H-IFN, high in IFN group; NKG2d, NK group 2D.
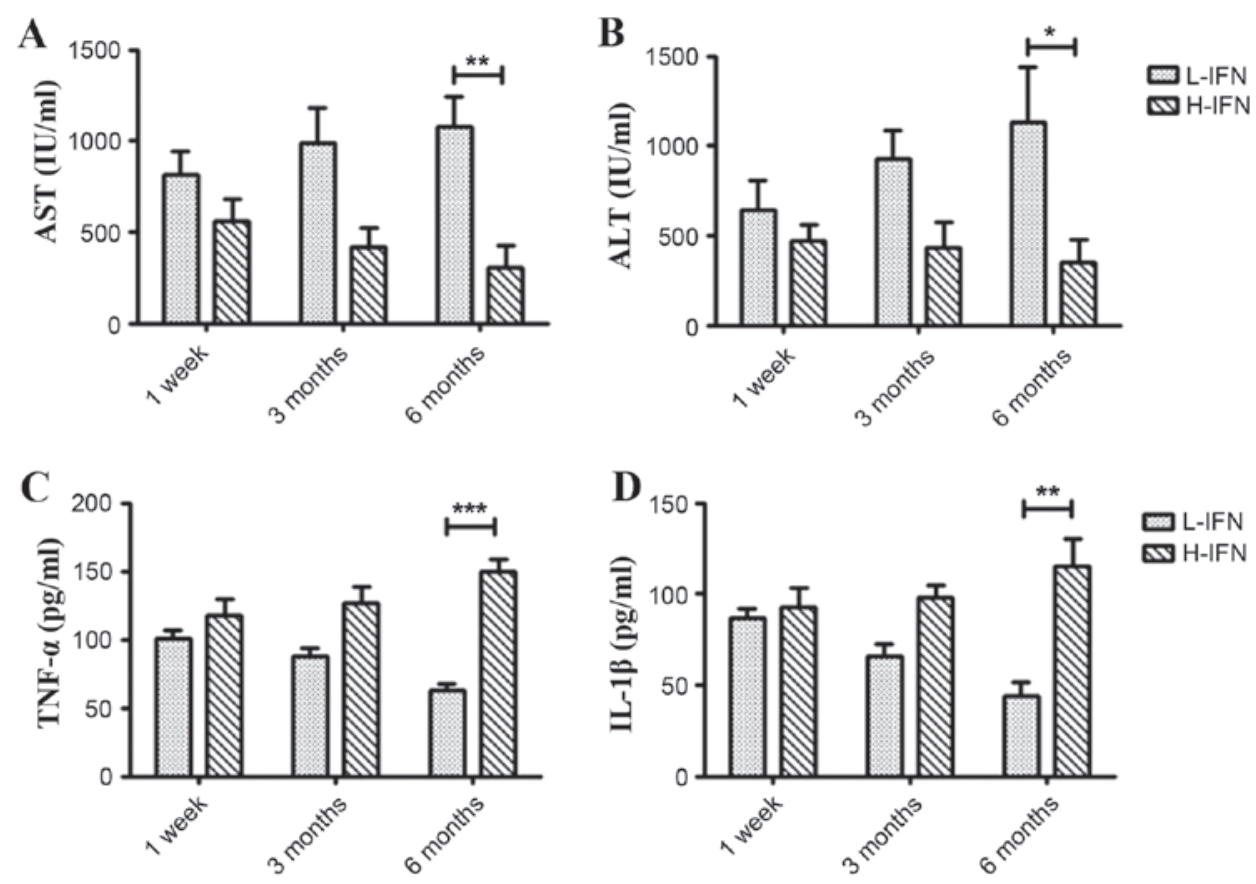

Figure 3. Potential indicators of rejection assessed. Expression of (A) AST, (B) ALT, (C) TNF- $\alpha$ and (D) IL-1 $\beta$ in serum of patients from the 2 groups, up to 6 months post-liver transplantation. AST, aspartate transaminase; ALT, alanine transaminase; TNF- $\alpha$, tumor necrosis factor- $\alpha$; IL, interleukin; IFN- $\gamma$, interferon- $\gamma ;$ L-IFN, low in IFN group; H-IFN, high in IFN group. ${ }^{*} \mathrm{P}<0.05,{ }^{* *} \mathrm{P}<0.01$ and ${ }^{* * *} \mathrm{P}<0.001$.

soluble IFN- $\gamma$, a percentage of CD8 ${ }^{+} \mathrm{IFN}-\gamma^{+}<40 \%$, developed acute rejection (35). In the present study, NK cells, were more active in patients with higher IFN- $\gamma$, who have a higher-risk of rejection, than those with a lower IFN- $\gamma$ density.

In summary, this study indicates that NK cells, as the primary source of IFN- $\gamma$, are activated after live transplantation and may lead to inflammation and acute rejection in LT patients. Therefore, inhibition of NK function may alleviate rejection and inflammation in LT patients. Further studies are required to explore the best protocols for blocking NK cell-mediated inflammation and rejection by suppressing NK cytotoxicity as well as mediating the secretion of IFN- $\gamma$. 


\section{References}

1. Thun MJ, DeLancey JO, Center MM, Jemal A and Ward EM The global burden of cancer: Priorities for prevention. Carcinogenesis 31: 100-110, 2010.

2. Yang LS, Shan LL, Saxena A and Morris DL: Liver transplantation: A systematic review of long-term quality of life. Liver Int 34: 1298-1313, 2014.

3. Yang LS, Shan LL, Saxena A and Morris DL: Liver transplantation: a systematic review of long-term quality of life. Liver international 34: 1298-313, 2014

4. Kim WR, Stock PG, Smith JM, Heimbach JK, Skeans MA, Edwards EB, Harper AM, Snyder JJ, Israni AK and Kasiske BL: OPTN/SRTR 2011 annual data report: Liver. Am J Transplant 13 (Suppl 1): 73-102, 2013.

5. Adam R, McMaster P, O'Grady JG, Castaing D, Klempnauer JL, Jamieson N, Neuhaus P, Lerut J, Salizzoni M, Pollard S, et al: Evolution of liver transplantation in Europe: Report of the European Liver Transplant Registry. Liver Transpl 9: 1231-1243, 2003 .

6. Kamei H, Al-Basheer M, Shum J, Bloch M, Wall W and Quan D: Comparison of short- and long-term outcomes after early versus late liver retransplantation: A single-center experience. J Surg Res 185: 877-882, 2013.

7. Jain A, Reyes J, Kashyap R, Dodson SF, Demetris AJ, Ruppert K, Abu-Elmagd K, Marsh W, Madariaga J, Mazariegos G, et al: Long-term survival after liver transplantation in 4,000 consecutive patients at a single center. Ann Sur 232: 490-500, 2000.

8. Mazzaferro V, Regalia E, Doci R, Andreola S, Pulvirenti A, Bozzetti F, Montalto F, Ammatuna M, Morabito A and Gennari L: Liver transplantation for the treatment of small hepatocellular carcinomas in patients with cirrhosis. N Engl J Med 334: 693-699, 1996.

9. Jonas S, Bechstein WO, Steinmüller T, Herrmann M, Radke C, Berg T, Settmacher U and Neuhaus P: Vascular invasion and histopathologic grading determine outcome after liver transplantation for hepatocellular carcinoma in cirrhosis. Hepatology 33: 1080-1086, 2001.

10. Klintmalm GB: International registry of liver tumors in liver transplantation. A registry update on hepatocellular carcinoma (HCC). Zentralbl Chir 125: 642-646, 2000.

11. Hanouneh IA, Macaron C, Lopez R, Aucejo F and Zein NN: Rate of tumor growth predicts recurrence of hepatocellular carcinoma after liver transplantation in patients beyond milan or ucsf criteria. Transplant Proc 43: 3813-3818, 2011.

12. Macaron C, Hanouneh IA, Lopez R, Aucejo F and Zein NN: Total tumor volume predicts recurrence of hepatocellular carcinoma after liver transplantation in patients beyond Milan or UCSF criteria. Transplant Proc 42: 4585-4592, 2010.

13. Confer BD, Choudhary M, Lopez R and Zein NN: Monitoring serial CD4 ${ }^{+} \mathrm{T}$-cell function after liver transplantation can be used to predict hepatocellular carcinoma recurrence. Transplant Proc 47: 217-222, 2015.

14. Hennedige T, Anil G and Madhavan K: Expectations from imaging for pre-transplant evaluation of living donor liver transplantation. World J Radiol 6: 693-707, 2014.

15. Bhoori S and Mazzaferro V: Current challenges in liver transplantation for hepatocellular carcinoma. Best Pract Res Clin Gastroenterol 28: 867-879, 2014.

16. Behboudi S, Boswell S and Williams R: Cell-mediated immune responses to alpha-fetoprotein and other antigens in hepatocellular carcinoma. Liver Int 30: 521-526, 2010.

17. Vivier E, Ugolini S, Blaise D, Chabannon C and Brossay L: Targeting natural killer cells and natural killer T cells in cancer. Nat Rev Immunol 12: 239-252, 2012.

18. Vesely MD, Kershaw MH, Schreiber RD and Smyth MJ: Natural innate and adaptive immunity to cancer. Annu Rev Immunol 29: $235-271,2011$
19. Paolini R, Bernardini G, Molfetta R and Santoni A: NK cells and interferons. Cytokine Growth Factor Rev 26: 113-120, 2015.

20. Cooper MA, Fehniger TA and Caligiuri MA: The biology of human natural killer-cell subsets. Trends Immunol 22: 633-640, 2001.

21. Miller JS, Soignier Y, Panoskaltsis-Mortari A, McNearney SA, Yun GH, Fautsch SK, McKenna D, Le C, Defor TE, Burns LJ, et al: Successful adoptive transfer and in vivo expansion of human haploidentical NK cells in patients with cancer. Blood 105: 3051-3057, 2005

22. Davis CT and Rizzieri D: Immunotherapeutic applications of NK cells. Pharmaceuticals 8: 250-256, 2015.

23. Horras CJ, Lamb CL and Mitchell KA: Regulation of hepatocyte fate by interferon- $\gamma$. Cytokine Growth Factor Rev 22: 35-43, 2011.

24. Guo Q, Lan P, Yu X, Han Q, Zhang J, Tian Z and Zhang C: Immunotherapy for hepatoma using a dual-function vector with both immunostimulatory and pim-3-silencing effects. Mol Cancer Ther 13: 1503-1513, 2014.

25. Zheng Q, Zhu YY, Chen J, Ye YB, Li JY, Liu YR, Hu ML, Zheng YC and Jiang JJ: Activated natural killer cells accelerate liver damage in patients with chronic hepatitis B virus infection. Clin Exp Immunol 180: 499-508, 2015.

26. Germani G, Rodriguez-Castro K, Russo FP, Senzolo M, Zanetto A, Ferrarese A and Burra P: Markers of acute rejection and graft acceptance in liver transplantation. World $\mathrm{J}$ Gastroenterol 21: 1061-1068, 2015.

27. Lee SD, Kim SH, Kong SY, Kim YK and Park SJ: Kinetics of B, $\mathrm{T}$, NK lymphocytes and isoagglutinin titers in $\mathrm{ABO}$ incompatible living donor liver transplantation using rituximab and basiliximab. Transpl Immunol 32: 29-34, 2015.

28. Rodríguez-Perálvarez M, Germani G, Tsochatzis E, Rolando N, Luong TV, Dhillon AP, Thorburn D, O'Beirne J, Patch D and Burroughs AK: Predicting severity and clinical course of acute rejection after liver transplantation using blood eosinophil count. Transpl Int 25: 555-563, 2012.

29. Germani G, Rodriguez-Castro K, Russo FP, Senzolo M, Zanetto A, Ferrarese A and Burra P: Markers of acute rejection and graft acceptance in liver transplantation. World J Gastroenterol 21: 1061-1068, 2015

30. Xing T, Zhong L, Qiu G, Huang L and Peng Z: Evolution of $\mathrm{CD} 4^{+} \mathrm{CD} 25$ (hi) $\mathrm{T}$ cell subsets in Aspergillus-infected liver transplantation recipients reduces the incidence of transplantation rejection via upregulating the production of anti-inflammatory cytokines. Genet Mol Res 13: 4932-4939, 2014

31. Sanchez-Fueyo A and Strom TB: Immunologic basis of graft rejection and tolerance following transplantation of liver or other solid organs. Gastroenterology 140: 51-64, 2011.

32. Strom TB and Koulmanda M: Recently discovered T cell subsets cannot keep their commitments. J Am Soc Nephrol 20: 1677-1680, 2009

33. Bathgate AJ,Lee P, Hayes PC and Simpson KJ: Pretransplantation tumor necrosis factor-alpha production predicts acute rejection after liver transplantation. Liver Transpl 6: 721-727, 2000.

34. Imagawa DK, Millis JM, Olthoff KM, Derus LJ, Chia D, Sugich LR, Ozawa M, Dempsey RA, Iwaki Y, Levy PJ, et al: The role of tumor necrosis factor in allograft rejection. I. Evidence that elevated levels of tumor necrosis factor-alpha predict rejection following orthotopic liver transplantation. Transplantation 50: 219-225, 1990.

35. Millán O, Rafael-Valdivia L, Torrademé E, López A, Fortuna V, Sánchez-Cabus S, López-Púa Y, Rimola A and Brunet M: Intracellular IFN- $\gamma$ and IL-2 expression monitoring as surrogate markers of the risk of acute rejection and personal drug response in de novo liver transplant recipients. Cytokine 61: 556-564, 2013. 